\title{
Chum salmon egg extracts induce upregulation of collagen type I and exert antioxidative effects on human dermal fibroblast cultures
}

This article was published in the following Dove Press journal:

Clinical Interventions in Aging

29 August 2016

Number of times this article has been viewed

\author{
Atsushi Yoshino' \\ Natalia Polouliakh ${ }^{1-3}$ \\ Akira Meguro' \\ Masaki Takeuchi ${ }^{1,4}$ \\ Tatsukata Kawagoe' \\ Nobuhisa Mizuki ${ }^{\prime}$ \\ 'Department of Ophthalmology \\ and Visual Science, Yokohama City \\ University Graduate School of \\ Medicine, Yokohama, Kanagawa, ${ }^{2}$ Sony \\ Computer Science Laboratories Inc., \\ Fundamental Research Laboratories, \\ ${ }^{3}$ Systems Biology Institute, Tokyo, \\ Japan; ${ }^{4}$ Inflammatory Disease Section, \\ National Human Genome Research \\ Institute, National Institutes of Health, \\ Bethesda, MD, USA
}

\begin{abstract}
Components of fish roe possess antioxidant and antiaging activities, making them potentially very beneficial natural resources. Here, we investigated chum salmon eggs (CSEs) as a source of active ingredients, including vitamins, unsaturated fatty acids, and proteins. We incubated human dermal fibroblast cultures for 48 hours with high and low concentrations of CSE extracts and analyzed changes in gene expression. Cells treated with CSE extract showed concentration-dependent upregulation of collagen type I genes and of multiple antioxidative genes, including OXR1, TXNRD1, and PRDX family genes. We further conducted in silico phylogenetic footprinting analysis of promoter regions. These results suggested that transcription factors such as acute myeloid leukemia-1a and cyclic adenosine monophosphate response element-binding protein may be involved in the observed upregulation of antioxidative genes. Our results support the idea that CSEs are strong candidate sources of antioxidant materials and cosmeceutically effective ingredients.
\end{abstract}

Keywords: fish egg, antiaging, gene expression analysis, antioxidative gene, phylogenetic footprinting analysis

\section{Introduction}

Skin is the body's largest organ, representing the interface between self and nonself. Skin aging is most prominently caused by extrinsic factors, mainly the permanent exposure of this organ to oxidative environmental stimuli, such as solar radiation, cigarette smoke, and other pollutants. ${ }^{1}$ The second most important contributor to skin aging is an intrinsic factor: the age-related mitochondrial enzyme dysfunction that inhibits epidermal regeneration. ${ }^{2}$

In the field of cosmetic science, skin aging is clinically characterized by water loss, reduced skin thickness, sagging, and wrinkle formation. ${ }^{3}$ At the molecular level, skin aging is characterized by reduced procollagen synthesis ${ }^{4-6}$ and degradation of the extracellular matrix, ${ }^{7}$ which mainly comprises collagen, glycosaminoglycan, and elastin. Aged skin fibroblasts become detached from the destabilized extracellular matrix, leading to a rounded and collapsed appearance. This in turn upregulates matrix metalloproteinase expression, activating a positive-feedback loop that further accelerates collagen matrix degradation. ${ }^{8}$ Based on evidence that oxidative stress plays pivotal roles in both intrinsic and extrinsic aging, it has been suggested that antioxidants may be an efficient means of defense against aging processes. ${ }^{9-11}$

Numerous studies have examined compounds derived from marine and botanical organisms that show cosmetically useful antioxidant and antiaging activities. ${ }^{12,13}$
Correspondence: Nobuhisa Mizuki Department of Ophthalmology and Visual Science, Yokohama City University, Fukuura 3-9, Kanazawa ward, Yokohama City, Kanagawa Prefecture 236-0004, Japan

Fax +8I 45 78| 9755

Email mizunobu@med.yokohama-cu.ac.jp (c)
hereby accept the Terms. Non-commercial uses of the work are permitted without any further permission from Dove Medical Press Limited, provided the work is properly attributed. For permission for commercial use of this work, please see paragraphs 4.2 and 5 of our Terms (https://www.dovepress.com/terms.php). 
Fish roe is a potential source of antiaging material, as it contains vitamins, proteins, unsaturated fatty acids, etc. ${ }^{14}$ In a previous study, Marotta et $\mathrm{al}^{15}$ demonstrated that nutraceuticals derived from beluga sturgeon's caviar (containing DNA, collagen elastin, and protein) robustly promoted the expression of collagen type I following in vitro supplementation.

In this study, we investigated the cosmetic use of chum salmon eggs (CSEs), called "Ikura" in Japanese. Differentiating them from other fish eggs, CSEs exhibit high concentrations of proteins $(27 \%-35 \%$ of total weight) and crude lipids (12\%-20\%), with $30 \%$ of the total lipids comprising phospholipids and $63 \%$ triglycerides. CSEs also show high content of vitamin A (50-3,000 IU/g), ${ }^{14}$ which is one of the most popular skin aging treatments. ${ }^{16}$ The xanthophyll carotenoid astaxanthin is the major contributor to the deep yellow-orange color of the muscle of salmon and is also found in CSEs. Astaxanthin is the precursor of vitamin $\mathrm{A}^{17}$ and per se quenches free radicals without being destroyed or becoming a pro-oxidant in the process. ${ }^{18}$ Using a repeated insult patch test, randomized clinical trials have shown improvements in several important parameters for perception of skin facial health and aging, following treatment with extract from eggs of Atlantic salmon ${ }^{19}$ (belongs to the same Salmonidae family as chum salmon). However, the effectiveness of CSEs in vitro has not yet been ascertained.

Here, we tested the efficacy of CSE extract using collagen synthesis ability as a measure of skin rejuvenation capacity. We also examined the alterations of gene expression related to oxidative stress response and reactive oxygen species (ROS) metabolism.

\section{Materials and methods Salmon egg extract preparation}

The ethics committee of Yokohama City University does not require approval to be sought for experiments with commercial cells. Raw CSEs (purchased online) were homogenized using the TissueRuptor rotor-stator device (Qiagen NV, Venlo, the Netherlands) and were diluted with phosphate-buffered saline to a concentration of $10^{5} \mathrm{mg} / \mathrm{L}$. This solution was centrifuged at 1,200 rpm for 5 minutes, and the supernatant was passed through a $0.22 \mu \mathrm{m}$ filter. CSE solutions were stored at $-80^{\circ} \mathrm{C}$ and, once thawed, were either used up or discarded.

\section{Cell culture}

Normal human neonatal skin fibroblasts (NB1RGB cells) were purchased from the RIKEN Cell Bank (Ibaraki, Japan). These cells were cultured in $\alpha$-MEM medium (Thermo Fisher Scientific, Waltham, MA, USA) supplemented with $10 \%$ fetal bovine serum (Thermo Fisher Scientific), penicillin
$100 \mathrm{U} / \mathrm{mL}$, and streptomycin $2.5 \mu \mathrm{L} / \mathrm{mL}$. Cells were plated at a concentration of $1 \times 10^{5}$ cells/dish $(100 \mathrm{~mm} \varphi)$, and the plates were supplemented with CSE solution at $80 \mu \mathrm{g} / \mathrm{mL}$ or $800 \mu \mathrm{g} / \mathrm{mL}$ or with phosphate-buffered saline as a negative control. Each experimental condition was replicated two times.

After incubation for 48 hours at $37^{\circ} \mathrm{C}$ in humidified air with $5 \% \mathrm{CO}_{2}$, total RNA was isolated from fibroblasts using TRIzol reagent (Thermo Fisher Scientific) according to the manufacturer's protocol. Extracted RNA was stored at $-80^{\circ} \mathrm{C}$.

\section{Gene expression assay}

Reverse transcription of total RNA was conducted using SuperScript II Reverse Transcriptase (Thermo Fisher Scientific), and the product was stored at $4^{\circ} \mathrm{C}$. Quantitative real time-polymerase chain reaction (RT-PCR) of the collagen $1 \mathrm{~A} 1$ and $1 \mathrm{~A} 2$ genes was performed using the StepOnePlus Real-Time PCR System (Thermo Fisher Scientific) with TaqMan gene expression assays. Relative quantification of gene expression was accomplished using the $2^{-\Delta \Delta \mathrm{Ct}}$ method, with glyceraldehyde-3-phosphate dehydrogenase gene as an endogenous control.

\section{Oxidative stress analysis PCR array}

After confirming the fold changes of collagen genes, we assessed the total antioxidant profile of the cells using Human Oxidative Stress RT ${ }^{2}$ Profiler PCR Array (Qiagen NV), which contains 84 key genes related to the oxidative stress response. All reactions were carried out using the StepOnePlus Real-Time PCR System according to the manufacturer's protocol. Relative expression values were calculated using the $2^{-\Delta \Delta \mathrm{Ct}}$ method. Genes with low absolute expression levels were excluded from further analyses, and the cut-off was set at $35 \mathrm{Ct}$.

All values from both the TaqMan assay and PCR array experiments are presented as the arithmetic means of two biological replicates.

\section{Promoter analysis in silico}

We performed transcription regulation analysis of 33 genes related to the oxidative stress response with fold changes over the defined threshold (induced) and of 31 genes with expression changes below the threshold (uninduced) in the $800 \mu \mathrm{g} / \mathrm{mL}$ CSE condition. The Sequence Homology in Higher Eukaryotes (in preparation) tool was used to perform the comparative genome promoter analysis in the human, mouse, and rat genome. ${ }^{20}$ We used sequences to 5,000 nucleotides upstream and 200 nucleotides downstream from the transcriptional start sites referenced in the DBTSS database. ${ }^{21}$ Analysis included the following 
steps: $\left.{ }^{20} 1\right)$ pairwise (human-mouse and human-rat) alignment ( $\geq 50 \%$ similarity);2) multiple alignment of human, mouse, and rat promoters; 3 ) computing the multiple alignment score ${ }^{22}$ for alignments conserved among three species in order to assign the strength of the identified orthologous alignment compared to a nonorthologous alignment; 4) scoring the human sequence with publicly available Transfac ${ }^{23}$ matrices; and 5) selecting the best scoring motifs using the Pareto front method. ${ }^{24}$ Additionally, we compared the transcription factor frequencies using the motif conservation score $^{25}$ for the induced gene set and for the uninduced gene set. Finally, transcription factors with motif conservation score $\geq 10$ were chosen as candidates for the transcription regulation of CSE-induced oxidative stress genes.

\section{Composition analysis of CSEs}

In order to presume what triggered observed changes involving multiple genes and transcription factors, we conducted a content analysis of CSEs, which was outsourced to a specialized institution, Japan Food Research Laboratories (Tokyo, Japan). The content of protein was quantified by the Kjeldahl method, and the total lipid content was measured by the acid hydrolysis method. The quantities of vitamin A, vitamin $\mathrm{E}$, and astaxanthin were determined by high performance liquid chromatography (HPLC) method.

\section{Results}

TaqMan assay revealed that supplementation with CSE extracts led to concentration-dependent upregulation of collagen type I mRNA expression (Figure 1). COL1A1 expression was $125 \%$ of the control expression level with CSEs of $80 \mu \mathrm{g} / \mathrm{mL}$ and $211 \%$ with CSEs of $800 \mu \mathrm{g} / \mathrm{mL}$. Similarly, COL1A2 expression was $136 \%$ of the control expression level with CSEs of $80 \mu \mathrm{g} / \mathrm{mL}$ and $262 \%$ with CSEs of $800 \mu \mathrm{g} / \mathrm{mL}$.

\section{Oxidative stress PCR array analysis}

Analysis of the oxidative stress pathway with the $\mathrm{RT}^{2}$ Profiler PCR Array revealed that 64 of the 84 genes were expressed in all samples, and we were able to obtain their meaningful relative expression values. To define a "prominent" increase or decrease in gene expression, we set the fold-change threshold to \pm 2 . Table 1 lists the genes showing prominent up- or downregulation, excluding those with low absolute expression levels, ie, for which the average threshold cycle is relatively high (>30) in the control, $80 \mu \mathrm{g} / \mathrm{mL}$, or $800 \mu \mathrm{g} / \mathrm{mL}$ condition. We found upregulation of many genes related to the oxidative stress response, with the greatest fold change observed

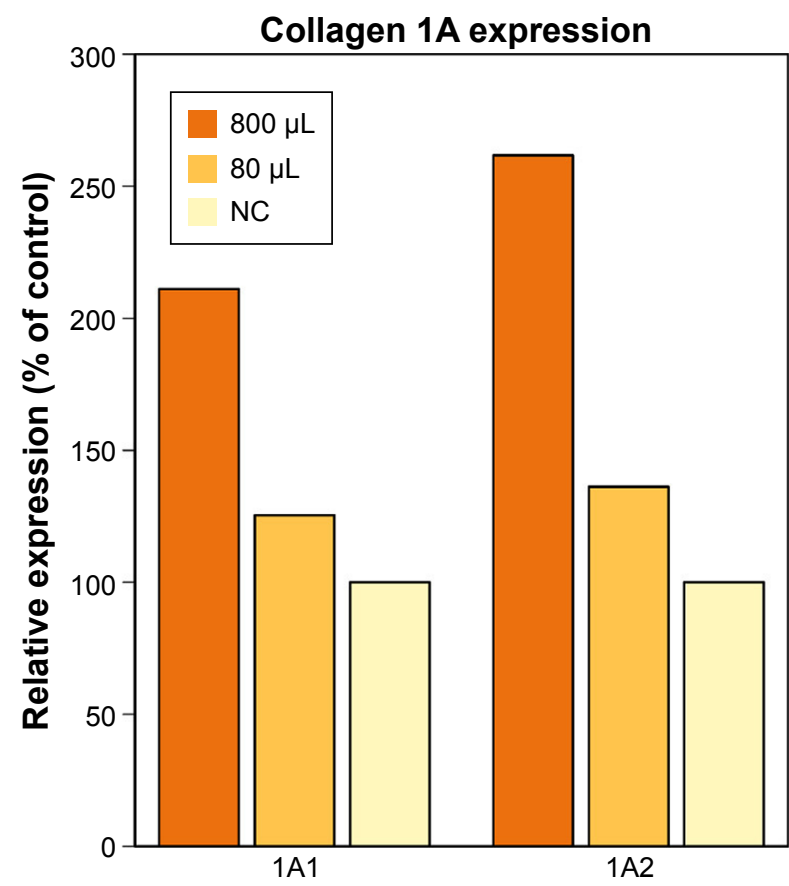

Figure I Expression of collagen type I gene with CSE extract supplementation relative to negative control.

Abbreviations: CSEs, chum salmon eggs; NC, negative control.

for the peroxiredoxin family genes (PRDX3, PRDX4, and PRDX5), thioredoxin (TXN) reductase 1 (TXNRD1), and oxidation resistance 1 (OXR1). We also observed notably high fold changes of PRDX1 (24.88 with $80 \mu \mathrm{g} / \mathrm{mL}$ and 3.01 with $800 \mu \mathrm{g} / \mathrm{mL}$ ); however, it was omitted from Table 1 due to its relatively low absolute expression levels.

The peroxiredoxin system and the glutathione peroxidase (GPX) system are the two main sets of oxidative stress response genes. Compared to the peroxiredoxin system genes, GPX system genes showed less prominent relative expressions, with most genes showing a change of only -1.5 - to 1.5 -fold. No GPXs (GPX1-GPX7) were highly upregulated, but several glutathione-related genes were prominently upregulated with $800 \mu \mathrm{g} / \mathrm{mL}$ CSEs, including MGST3 (2.16-fold), GCLM (2.14-fold), and GSTP1 (2.12-fold).

Other major ROS metabolism genes, including catalase and superoxide dismutases (SOD1-SOD3), also did not exhibit prominent upregulation. SOD3 showed upregulated expression ( 2.15 in $80 \mu \mathrm{g} / \mathrm{mL}$ and 1.52 in $800 \mu \mathrm{g} / \mathrm{mL}$ ), but its absolute expression was below the criteria for inclusion in Table 1 .

The other prominently increased genes showed diverse primary roles, including peroxidase activity (PXDN), stabilizing proteins against aggregation (HSPA1A), iron storage (FTH), reduction of antioxidant molecules (NQO1), and antioxidant molecule preparation (HMOX1). However, 
Table I Differentially regulated genes involved in oxidative resistance and reactive oxygen species metabolism

\begin{tabular}{|c|c|c|c|}
\hline \multirow[t]{2}{*}{ Gene } & \multirow[t]{2}{*}{ Description } & \multicolumn{2}{|c|}{ Fold change } \\
\hline & & $80 \mu \mathrm{g} / \mathrm{mL}$ & $800 \mu \mathrm{g} / \mathrm{mL}$ \\
\hline SCARA3 & Scavenger receptor class $A$, member 3 & -1.88 & -5.29 \\
\hline DUSPI & Dual specificity phosphatase I & -2.69 & 1.33 \\
\hline$A O X I$ & Aldehyde oxidase I & -1.89 & -2.65 \\
\hline VIMP & Selenoprotein S & -1.87 & -2.65 \\
\hline GSTPI & Glutathione S-transferase pi I & 1.07 & 2.12 \\
\hline HSPAIA & Heat shock 70 kDa protein IA & 2.13 & 1.06 \\
\hline PXDN & Peroxidasin homolog (Drosophila) & 2.14 & 1.52 \\
\hline GCLM & Glutamate-cysteube ligase, catalytic subunit & 1.89 & 2.14 \\
\hline MGST3 & Microsomal glutathione S-transferase 3 & 1.52 & 2.16 \\
\hline$T X N$ & Thioredoxin & 1.09 & 2.19 \\
\hline FTHI & Ferritin, heavy polypeptide I & -1.32 & 4.25 \\
\hline NQOI & $\mathrm{NAD}(\mathrm{P}) \mathrm{H}$ dehydrogenase, quinone I & 2.13 & 4.28 \\
\hline HMOXI & Heme oxygenase (decycling) I & 1.84 & 4.39 \\
\hline$S R X N$ & Sulfiredoxin I & 4.41 & 8.75 \\
\hline RNF7 & Ring finger protein 7 & 3.10 & 4.42 \\
\hline PRDX3 & Peroxiredoxin 3 & 8.52 & 4.22 \\
\hline TXNRDI & Thioredoxin reductase I & 6.13 & 12.36 \\
\hline PRDX4 & Peroxiredoxin 4 & 17.55 & 17.50 \\
\hline PRDX5 & Peroxiredoxin 5 & 17.69 & 12.60 \\
\hline OXRI & Oxidation resistance I & 24.87 & 17.72 \\
\hline
\end{tabular}

Note: The values above 2.0 or below -2.0 are shown in bold.

each of these genes is directly or indirectly involved in the antioxidative status of the cell.

\section{Promoter analysis in silico}

Table 2 presents the transcription factor-binding motifs that are evolutionarily conserved and that showed $>50 \%$ similarity to the consensus sequence. We identified 16 such transcription factors, nine of which are described in this section.

The promoters of several induced genes included transcription factors of acute myeloid leukemia-1a (AML-1a), which is involved in the anti-inflammatory response, ${ }^{26}$ and of the cyclic adenosine monophosphate response elementbinding protein (CREB), which is involved in hyaluronic acid synthesis ${ }^{27}$ and in regulating development, stress, and inflammatory pathways in fibroblasts. ${ }^{28}$

The PRDX5, PRDX3, PRDX1, and GCTP1 genes shared the AML-1a transcription factor-binding motif. The PRDX4, HMOX1, FTH1, and DUSP1 genes shared the CREB transcription factor-binding motif. As an example, Figure S1 shows the CREB identified in the orthologous promoters of the PRDX4 gene in humans, mice, and rats. Based on the motifs shared by the promoters, we created a hypothetical map of the transcriptional regulation using the CellDesigner software (Figure 2). ${ }^{29}$

The promoter of the downregulated DUSP1 gene was tightly occupied by CREBs, including CRE-BP1,
CRE-BP1:c-Jun, and CREB:ATF unit motifs. HMOX1, FTH1, and SQSTM1 shared the CREB and NF-E2 transcription factors. SQSTM1 showed FOXO1- and NRF2-binding motifs in the promoter but is not included in Table 1 due to its comparatively low fold increase in expression (1.5 in $800 \mu \mathrm{g} / \mathrm{mL}$ ). The EGR1 motif was identified in the promoters of the PRDX5 and TXN genes. EGR1 is a well-known target of the estrogen receptor (ESR 1$) ;{ }^{30}$ thus, we conjectured that ESR1 might mediate CES signaling, with consequent activation of the AML-1a and Elk1 transcription factors.

\section{Discussion}

This study represents an initial step toward investigating the beneficial effects of chum salmon egg extract on human dermal fibroblast cell cultures. Our results revealed that treatment with CSE extract enhanced the mRNA expression of type I procollagen (COL1A1 and COL1A2) and led to upregulation of peroxiredoxin system components and other antioxidant genes. Phylogenetic footprinting of the affected antioxidant genes predicted 16 transcription factors, including AML-1a and CREB, to be binding promoter regions of genes induced by CSE supplementation.

A previous study has shown the enhancement of type I collagen in human dermal fibroblasts following supplementation with extracts of beluga sturgeon's caviar with added $\mathrm{CoQ}_{10}$ and selenium, called LD- $1227 .{ }^{15}$ They reported a $167 \%$ increase in collagen type I mRNA with supplementation 


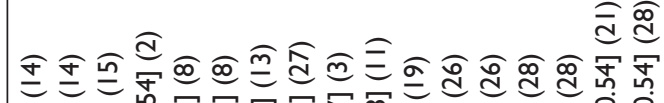

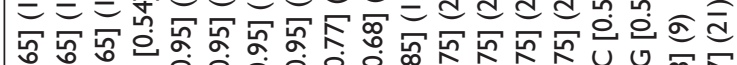

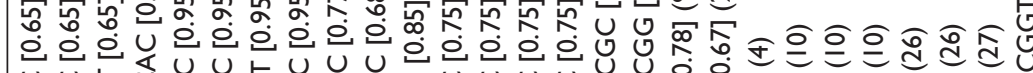

U U U

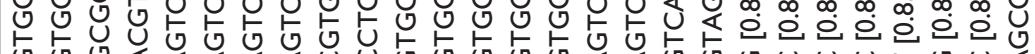

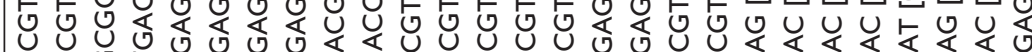

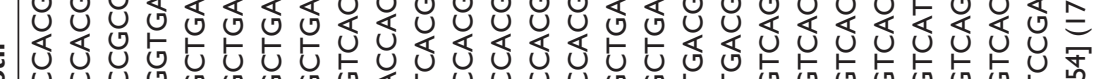

U

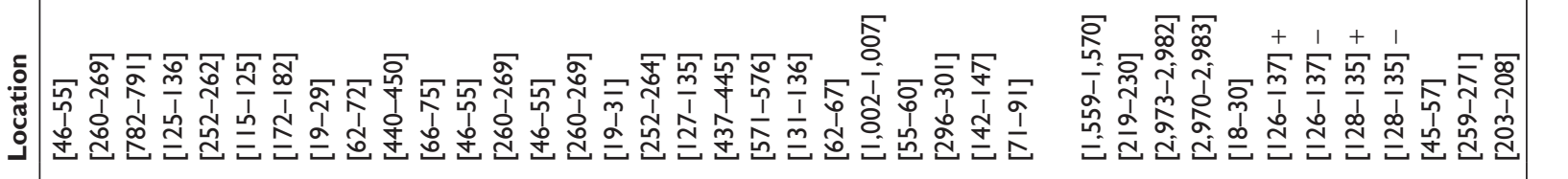

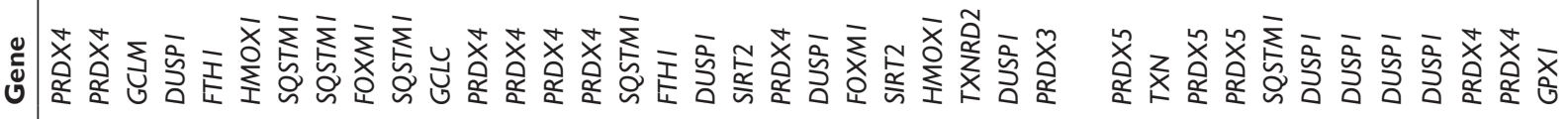

흥 흥흥 흥

흥 흥 흥흥흥 흥 흥 흇

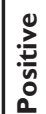

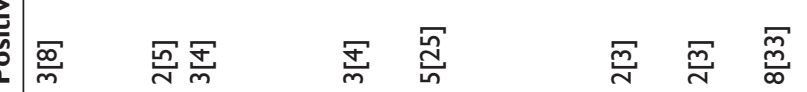

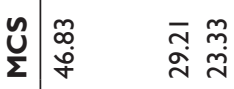

$\underset{\sim}{\stackrel{m}{\sim}} \stackrel{\sim}{\sim}$

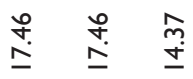

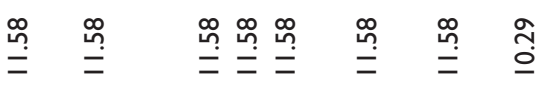

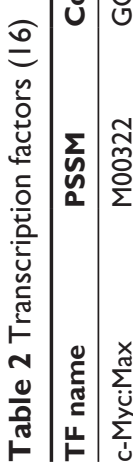

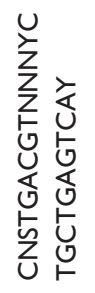

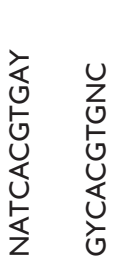

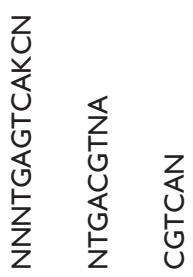

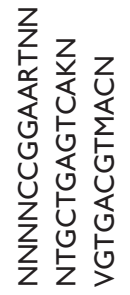

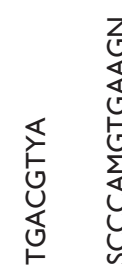

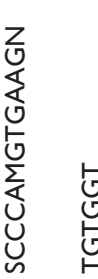

흥ํㅇ

๙ิิ

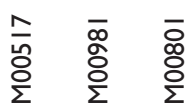

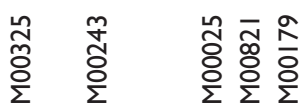

ఫे

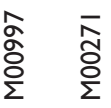

峞荒

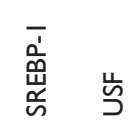

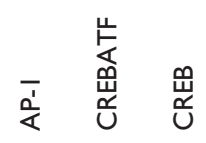

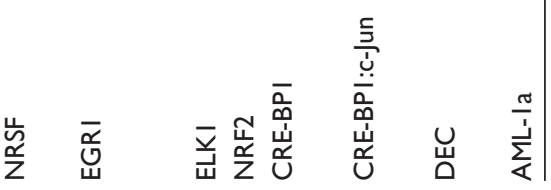




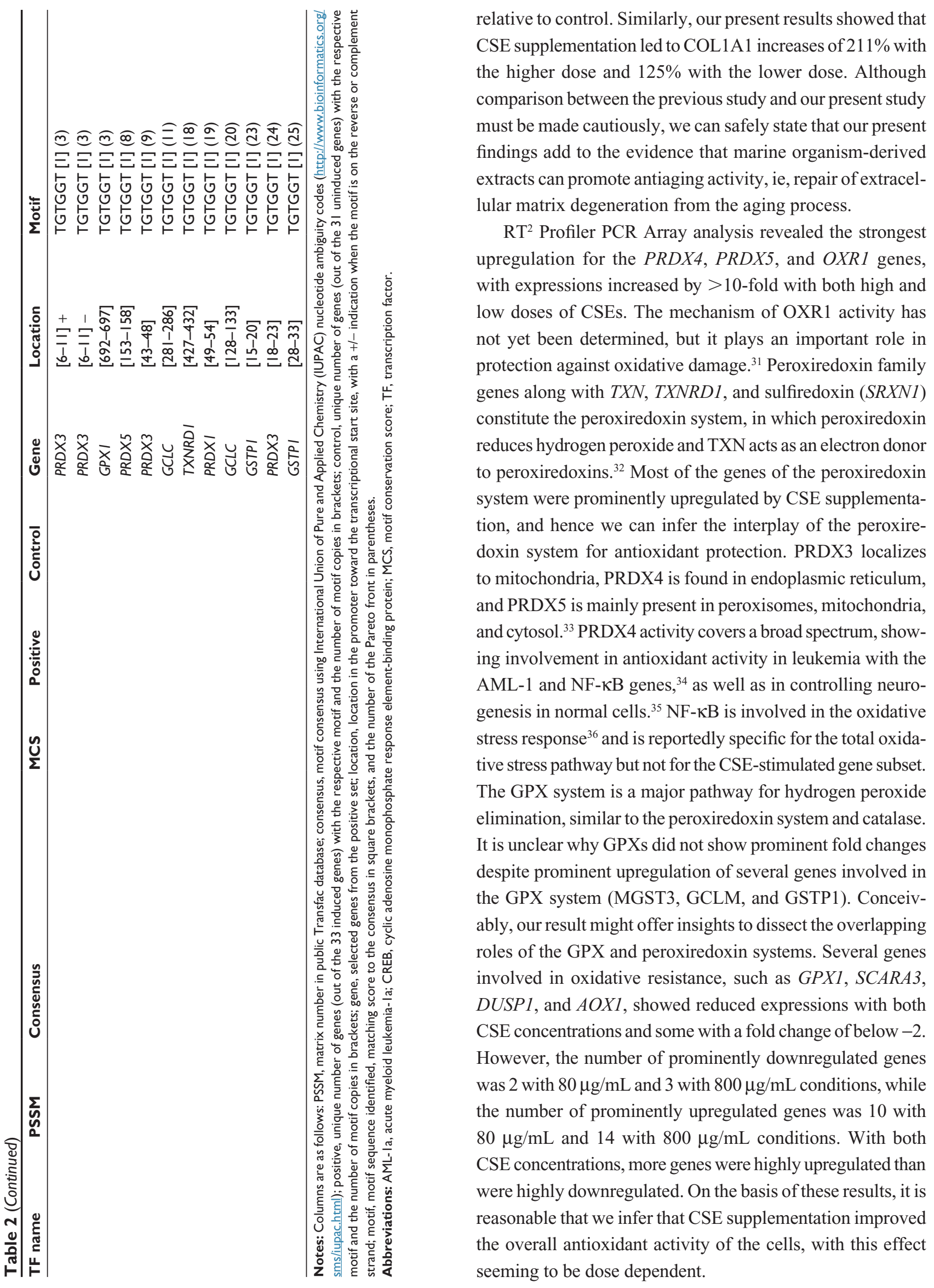




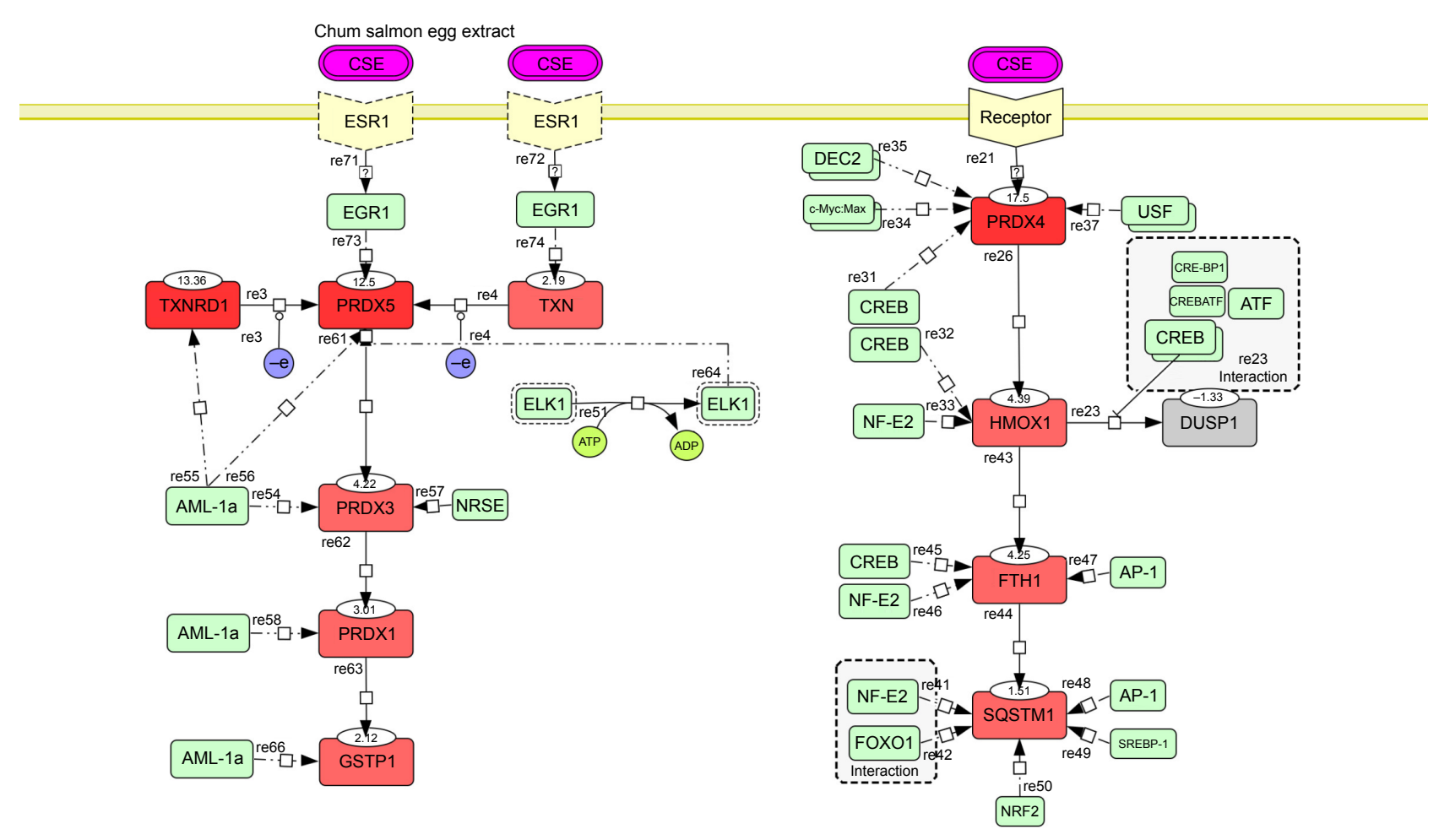

Figure 2 Hypothetical map of transcription regulation.

Notes: Red rectangles represent differentially regulated genes with the fold change indicated at the top edge. Solid arrows show the proposed gene activation cascade based on the transcription factor motifs shared by the genes, the activation levels, and available data from the literature. Green rectangles represent transcription factors whose sites are evolutionarily conserved among three species, with dashed arrows pointing to the associated genes. Pairs of overlapping green rectangles indicate that there were two copies of the identified motif. Dashed rectangles enclose interacting transcription factors. Hypothetical receptor genes are shown in yellow.

Abbreviation: CSEs, chum salmon eggs.

In our dataset, we identified two main kinds of transcription factors: inflammation-response transcription factors (AML-1a, EGR1, and ELK1) ${ }^{37}$ and DNA damage repair and antioxidant activity transcription factors (CREB, NF-E2, NRF2, c-Myc:Max, ${ }^{38}$ USF, ${ }^{39}$ and FOXO1). The involvement of the oncogene AML-1a was surprising. On the other hand, CREB is well known for its role in limiting ROS toxicity in the brain, ${ }^{40,41}$ as well as its involvement as an effectorlike nuclear protein in stress and inflammatory response pathways. ${ }^{28}$ Together with DUSP1, CREB elicits negative regulation of cellular proliferation under oxidative stress. FOXO1 is a longevity transcription factor ${ }^{42}$ that promotes repair of DNA oxidative damage, together with the NF-E2 transcription factor ${ }^{43}$ whose motifs were presently identified in the promoters of the HMOX1, FTH1, and SQSTM1 genes. NRF2, whose motif was found in the SQSTM1 promoter region, is well known for its involvement in oxidative stress responses ${ }^{44}$ and photoaging resistance..$^{45}$ EGR1 induces cell apoptosis upon UV irradiation stress, ${ }^{46}$ and its involvement presupposes an involvement of estrogen receptor (ESR1) in CSE-induced signaling, as shown in Figure 2.

Although it is difficult to predict precisely what triggers the observed beneficial modulations involving numerous genes and transcription factors, we can hypothesize several plausible responsible molecules. Table 3 describes the nourishing qualities of chum salmon egg. One candidate molecule is astaxanthin, which is a precursor of vitamin A17 and an effective antioxidant. Due to its beneficial properties, astaxanthin is already included in some cosmeceutical products, for example, Fujifilm Astalift lineup (http://www.astalift.com.sg). Other candidate active components are yolk-specific proteins, such as phosvitin and lipovitellin. Phosvitin is one of the most phosphorylated proteins in nature and possesses a strong metal-binding ability that makes it useful in antioxidant defense ${ }^{47}$ and immunoprotection. ${ }^{48}$ Lipovitellin is classified as a glycolipoprotein and is involved in the

Table 3 The composition of chum salmon egg

\begin{tabular}{lll}
\hline Content & $\begin{array}{l}\text { Concentration } \\
\text { (per 100 g) }\end{array}$ & Examples \\
\hline Fatty acids & $14.0 \mathrm{~g}$ & $\begin{array}{l}\text { Oleic acid }(\omega 9) \text {, linoleic acid }(\omega 6), \\
\text { palmitoleic acid }(\omega 7) \text {, and DHA and } \\
\text { EPA }(\omega 3)\end{array}$ \\
Proteins & $31.2 \mathrm{~g}$ & Phosvitin, lipovitellin, and lysozyme \\
Vitamin E & $7.2 \mathrm{mg}$ & \\
Vitamin A & $374 \mu \mathrm{g}$ & \\
Astaxanthin & $0.99 \mathrm{mg}$ & \\
\hline
\end{tabular}

Abbreviations: DHA, Docosahexaenoic acid; EPS, eicosapentaenoic acid. 
storage of nutrients for growth as well as the immune defenses of embryos and larva. ${ }^{49}$ Moreover, vitellogenin, the precursor of phosvitin and vitellin, is broadly conserved among oviparous animals and is synthesized in the liver and incorporated into oocytes under the control of estrogen. ${ }^{50}$ Both environmental and injected estrogens influence vitellogenin expression and blood concentration. ${ }^{51,52}$ Thus, the presence of vitellogenin in CSEs might induce EGR1 upregulation, prompting further potential positive effects on skin rejuvenation ${ }^{53}$ and skin esthetics. There remains a need for further investigations of estrogen receptors in relation to skin aging.

\section{Conclusion}

In conclusion, our present findings suggested the possibility that CSEs could be effectively used as a source of cosmeceutically active ingredients that exert antiaging and antioxidative effects on the skin. We have also hypothesized the pathway connecting stimulation with CSE extract with the upregulation of several antioxidant genes involving transcription factors, which is characterized by certain beneficial effects to the cell.

\section{Disclosure}

The authors report no conflicts of interest in this work.

\section{References}

1. Kammeyer A, Luiten RM. Oxidation events and skin aging. Ageing Res Rev. 2015;21:16-29.

2. Velarde MC, Demaria M, Melov S, Campisi J. Pleiotropic age-dependent effects of mitochondrial dysfunction on epidermal stem cells. Proc Natl Acad Sci U S A. 2015;112(33):10407-10412.

3. Marrakchi S, Maibach HI. Biophysical parameters of skin: map of human face, regional, and age-related differences. Contact Dermatitis. 2007;57(1):28-34.

4. Hwang KA, Yi BR, Choi KC. Molecular mechanisms and in vivo mouse models of skin aging associated with dermal matrix alterations. Lab Anim Res. 2011;27(1):1-8.

5. Fisher GJ, Datta S, Wang Z, et al. c-Jun-dependent inhibition of cutaneous procollagen transcription following ultraviolet irradiation is reversed by all-trans retinoic acid. J Clin Invest. 2000;106(5):663-670.

6. Imai S, Kitano H. Heterochromatin islands and their dynamic reorganization: a hypothesis for three distinctive features of cellular aging. Exp Gerontol. 1998;33(6):555-570.

7. Quan T, He T, Kang S, Voorhees JJ, Fisher GJ. Solar ultraviolet irradiation reduces collagen in photoaged human skin by blocking transforming growth factor-beta type II receptor/Smad signaling. Am J Pathol. 2004;165(3):741-751.

8. Fisher GJ, Quan T, Purohit T, et al. Collagen fragmentation promotes oxidative stress and elevates matrix metalloproteinase- 1 in fibroblasts in aged human skin. Am J Pathol. 2009;174(1):101-114.

9. Imai S. Is Sirt1 a miracle bullet for longevity? Aging Cell. 2007;6(6): 735-737.

10. Wolf AM, Nishimaki K, Kamimura N, Ohta S. Real-time monitoring of oxidative stress in live mouse skin. J Invest Dermatol. 2014;134(6): 1701-1709.

11. Harman D. Free radical theory of aging. Mutat Res. 1992;275(3-6): $257-266$.
12. Kim SK. Marine cosmeceuticals. J Cosmet Dermatol. 2014;13:56-67.

13. Zhu W, Gao J. The use of botanical extracts as topical skin-lightening agents for the improvement of skin pigmentation disorders. J Investig Dermatol Symp Proc. 2008;13(1):20-24.

14. Bledsoe GE, Bledsoe CD, Rasco B. Caviars and fish roe products. Crit Rev Food Sci Nutr. 2003;43(3):317-356.

15. Marotta F, Polimeni A, Solimene U, et al. Beneficial modulation from a high-purity caviar-derived homogenate on chronological skin aging. Rejuvenation Res. 2012;15(2):174-177.

16. Mukherjee S, Date A, Patravale V, Korting HC, Roeder A, Weindl G. Retinoids in the treatment of skin aging: an overview of clinical efficacy and safety. Clin Interv Aging. 2006;1(4):327-348.

17. Yamashita E, Arai S, Matsuno T. Metabolism of xanthophylls to vitamin A and new apocarotenoids in liver and skin of black bass, Micropterus salmoides. Comp Biochem Physiol B Biochem Mol Biol. 1996;113(3): 485-489.

18. Kidd P. Astaxanthin, cell membrane nutrient with diverse clinical benefits and anti-aging potential. Altern Med Rev. 2011;16(4):355-364.

19. Lønne GK, Gammelsaeter R, Haglerød C. Composition characterization and clinical efficacy study of a salmon egg extract. Int J Cosmet Sci. 2013;35(5):515-522.

20. Polouliakh N, Natsume T, Harada H, Fujibuchi W, Horton P. Comparative genomic analysis of transcription regulation elements involved in human MAP kinase G-protein coupling pathway. J Bioinform Comput Biol. 2006;4(2):469-482.

21. Suzuki Y, Yamashita R, Nakai K, Sugano S. DBTSS: DataBase of human Transcriptional Start Sites and full-length cDNAs. Nucleic Acids Res. 2002;30(1):328-331.

22. Polouliakh N, Kitano H, inventor; Motif finding program, information processor and motif finding method. US 2014/0163894 A1, Edn. G06F 19/18 1-25. 2014.

23. Wingender E, Dietze P, Karas H, Knüppel R. TRANSFAC: a database on transcription factors and their DNA binding sites. Nucleic Acids Res. 1996;24(1):238-241.

24. Reguera C, Sánchez MS, Ortiz MC, Sarabia LA. Pareto-optimal front as a tool to study the behaviour of experimental factors in multi-response analytical procedures. Anal Chim Acta. 2008;624(2):210-222.

25. Xie X, Lu J, Kulbokas EJ, et al. Systematic discovery of regulatory motifs in human promoters and 3' UTRs by comparison of several mammals. Nature. 2005;434(7031):338-345.

26. Tsubaki M, Takeda T, Sakamoto K, et al. Bisphosphonates and statins inhibit expression and secretion of MIP-1_ via suppression of Ras/MEK/ ERK/AML-1A and Ras/PI3K/Akt/AML-1A pathways. Am J Cancer Res. 2015;5(1):168-179.

27. Maeda-Sano K, Gotoh M, Morohoshi T, Someya T, Murofushi H, Murakami-Murofushi K. Cyclic phosphatidic acid and lysophosphatidic acid induce hyaluronic acid synthesis via CREB transcription factor regulation in human skin fibroblasts. Biochim Biophys Acta. 2014; 1841(9):1256-1263.

28. Jeffrey KL, Camps M, Rommel C, Mackay CR. Targeting dual-specificity phosphatases: manipulating MAP kinase signalling and immune responses. Nat Rev Drug Discov. 2007;6(5):391-403.

29. Funahashi A, Morohashi M, Kitano H, Tanimura N. CellDesigner: a process diagram editor for gene-regulatory and biochemical networks. Biosilico. 2003;1(5):159-162.

30. Kim HR, Kim YS, Yoon JA, et al. Egr1 is rapidly and transiently induced by estrogen and bisphenol A via activation of nuclear estrogen receptordependent ERK1/2 pathway in the uterus. Reprod Toxicol. 2014;50: 60-67.

31. Volkert MR, Elliott NA, Housman DE. Functional genomics reveals a family of eukaryotic oxidation protection genes. Proc Natl Acad Sci U S A. 2000;97(26):14530-14535.

32. Lu J, Holmgren A. The thioredoxin antioxidant system. Free Radic Biol Med. 2014;66:75-87.

33. Rhee SG, Woo HA, Kil IS, Bae SH. Peroxiredoxin functions as a peroxidase and a regulator and sensor of local peroxides. J Biol Chem. 2012;287(7):4403-4410. 
34. Zhang Y, Emmanuel N, Kamboj G, et al. PRDX4, a member of the peroxiredoxin family, is fused to AML1 (RUNX1) in an acute myeloid leukemia patient with a $\mathrm{t}(\mathrm{X} ; 21)(\mathrm{p} 22 ; \mathrm{q} 22)$. Genes Chromosom Cancer. 2004;40(4):365-370.

35. Yan Y, Wladyka C, Fujii J, Sockanathan S. Prdx4 is a compartmentspecific $\mathrm{H}_{2} \mathrm{O}_{2}$ sensor that regulates neurogenesis by controlling surface expression of GDE2. Nat Commun. 2015;6:7006.

36. Dayem AA, Choi HY, Kim JH, Cho SG. Role of oxidative stress in stem, cancer, and cancer stem cells. Cancers (Basel). 2010;2(2):859-884.

37. Cavalcanti FN, Lucas TF, Lazari MF, Porto CS. Estrogen receptor ESR1 mediates activation of ERK1/2, CREB, and ELK1 in the corpus of the epididymis. J Mol Endocrinol. 2015;54(3):339-349.

38. Nichols AF, Itoh T, Zolezzi F, Hutsell S, Linn S. Basal transcriptional regulation of human damage-specific DNA-binding protein genes DDB1 and DDB2 by Sp1, E2F, N-myc and NF1 elements. Nucleic Acids Res. 2003;31(2):562-569.

39. Baron Y, Corre S, Mouchet N, Vaulont S, Prince S, Galibert MD. USF-1 is critical for maintaining genome integrity in response to UV-induced DNA photolesions. PLoS Genet. 2012;8(1):e1002470.

40. Lee B, Cao R, Choi YS, et al. The CREB/CRE transcriptional pathway: protection against oxidative stress-mediated neuronal cell death. J Neurochem. 2009;108(5):1251-1265.

41. Zhang L, Jope RS. Oxidative stress differentially modulates phosphorylation of ERK, p38 and CREB induced by NGF or EGF in PC12 cells. Neurobiol Aging. 1999;20(3):271-278.

42. Li Y, Wang WJ, Cao H, et al. Genetic association of FOXO1A and FOXO3A with longevity trait in Han Chinese populations. Hum Mol Genet. 2009;18(24):4897-4904.

43. Timme-Laragy AR, Karchner SI, Franks DG, et al. Nrf2b, novel zebrafish paralog of oxidant-responsive transcription factor NF-E2related factor 2 (NRF2). J Biol Chem. 2012;287(7):4609-4627.

44. Gruber F, Ornelas CM, Karner S, et al. Nrf2 deficiency causes lipid oxidation, inflammation and matrix-protease expression in DHA supplemented and UVA irradiated skin fibroblasts. Free Radic Biol Med 2015;(88Pt B):439-451.
45. Tian FF, Zhang FF, Lai XD, et al. Nrf2-mediated protection against UVA radiation in human skin keratinocytes. Biosci Trends. 2011;5(1): 23-29.

46. Arora S, Wang Y, Jia Z, et al. Egr1 regulates the coordinated expression of numerous EGF receptor target genes as identified by ChIP-on-chip. Genome Biol. 2008;9(11):R166.

47. Lee SK, Han JH, Decker EA. Antioxidant activity of phosvitin in phosphatidylcholine liposomes and meat model systems. J Food Sci. 2002;67(1):37-41

48. Wang S, Wang Y, Ma J, Ding Y, Zhang S. Phosvitin plays a critical role in the immunity of zebrafish embryos via acting as a pattern recognition receptor and an antimicrobial effector. J Biol Chem. 2011; 286(25):22653-22664.

49. Zhang J, Zhang S. Lipovitellin is a non-self recognition receptor with opsonic activity. Mar Biotechnol. 2011;13:441-450.

50. Bergink EW, Wallace RA, Van De Berg JA, Bos ES, Gruber M, Ab G. Estrogen-induced synthesis of yolk proteins in roosters. Am Zool. 1974; 14:1177-1193.

51. Idler DR, Campbell CM. Gonadotropin stimulation of estrogen and yolk precursor synthesis in juvenile rainbow trout. Gen Comp Endocrinol. 1980;41:384-391.

52. Tada N, Nakao A, Hoshi H, Saka M, Kamata Y. Vitellogenin, a biomarker for environmental estrogenic pollution, of Reeves' pond turtles: analysis of similarity for its amino acid sequence and cognate mRNA expression after exposure to estrogen. J Vet Med Sci. 2008;70: 227-234.

53. Cortés-Gallegos V, Villanueva GL, Sojo-Aranda I, Santa Cruz FJ. Inverted skin changes induced by estrogen and estrogen/glucocorticoid on aging dermis. Gynecol Endocrinol. 1996;10:125-128. 


\section{Supplementary material}

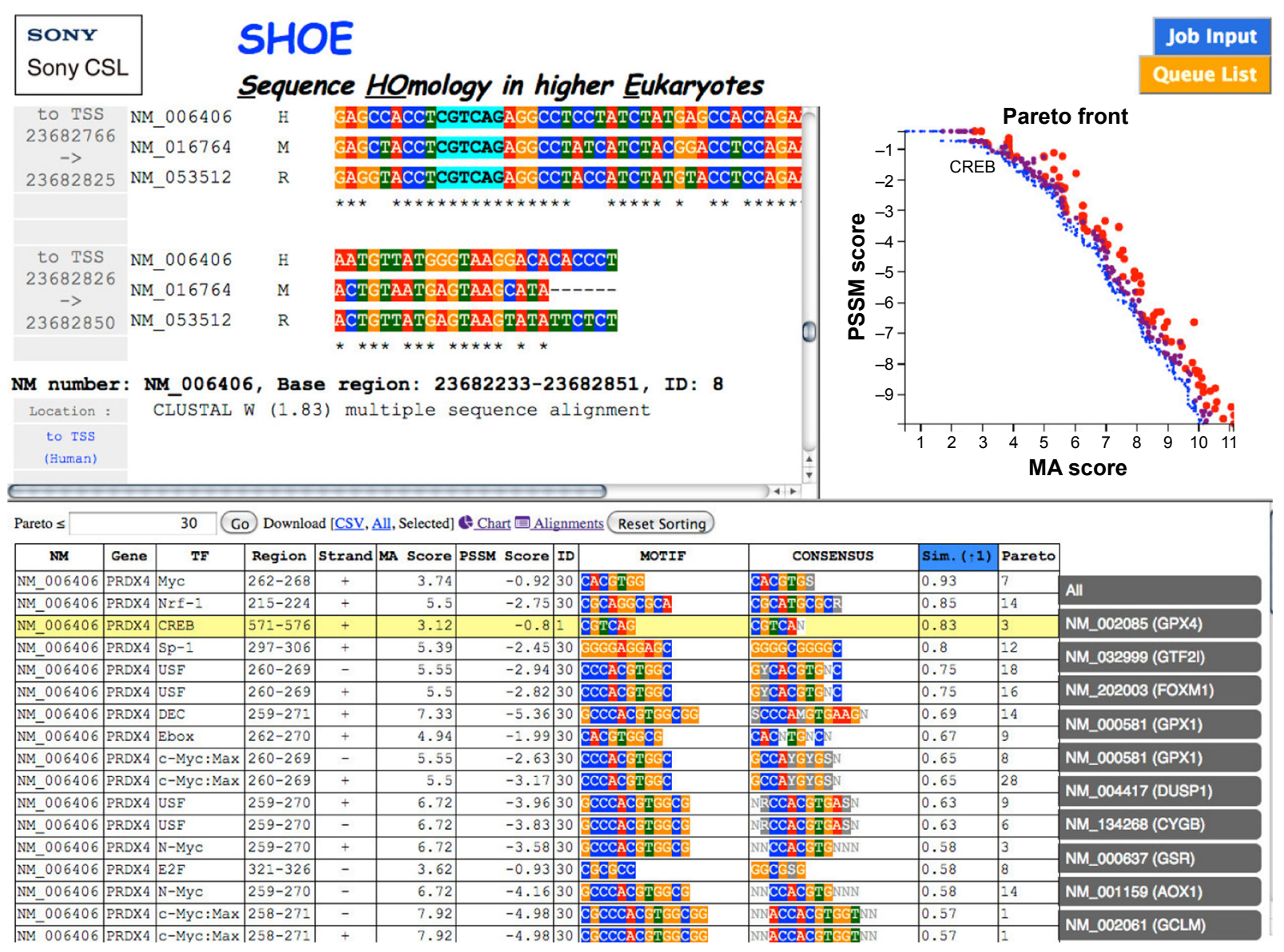

Figure SI Visualization of the results of promoter analysis of the PRDX4 gene, especially the CREB transcription factor-binding motif.

Notes: The upper left part of the figure shows the orthologous species alignment. The upper right panel shows the Pareto front graph with the CREB motif allocated on the first Pareto front, indicating its strong cross-species conservation and strong matching with a known matrix. The table below lists all candidate motifs with their similarity matching score to the consensus motif and their Pareto front number.

Abbreviation: CREB, cyclic adenosine monophosphate response element-binding protein.

Clinical Interventions in Aging

\section{Publish your work in this journal}

Clinical Interventions in Aging is an international, peer-reviewed journal focusing on evidence-based reports on the value or lack thereof of treatments intended to prevent or delay the onset of maladaptive correlates of aging in human beings. This journal is indexed on PubMed Central, MedLine,

\section{Dovepress}

CAS, Scopus and the Elsevier Bibliographic databases. The manuscript management system is completely online and includes a very quick and fair peer-review system, which is all easy to use. Visit http://www.dovepress. com/testimonials.php to read real quotes from published authors. 